\title{
Enhancement of ethanol oxidation on Pd nanoparticles supported on carbon-antimony tin oxide hybrids unveils the relevance of electronic effects
}

\author{
Gabriel M. Alvarenga, Irã B. Coutinho Gallo, Hebe M. Villullas* \\ Universidade Estadual Paulista (UNESP), Instituto de Química, Araraquara, 14800-900 Araraquara, SP, Brazil
}

\section{A R T I C L E I N F O}

\section{Article history:}

Received 15 November 2016

Revised 19 January 2017

Accepted 6 February 2017

Available online 1 March 2017

\section{Keywords:}

Pd nanoparticles

Hybrid supports

Ethanol oxidation

Electronic properties

\begin{abstract}
A B S T R A C T
A comparative study of activity toward ethanol oxidation was carried out for catalysts having the same loading of identical Pd nanoparticles supported on carbon-oxide hybrids containing antimony tin oxide $\left(\mathrm{Sb}_{2} \mathrm{O}_{5} / \mathrm{SnO}_{2}-\mathrm{ATO}\right)$ in different amounts (20, 30 and $\left.40 \mathrm{wt} . \%\right)$. Enhanced catalytic activity was observed for Pd nanoparticles supported on C-ATO hybrids. X-ray absorption spectroscopy experiments carried out around the $\mathrm{Pd} \mathrm{L}_{3}$ edge evidenced an increase in the electronic occupancy of the Pd $4 \mathrm{~d}$ band indicating an electronic transfer from the hybrid supports to the Pd particles. A strong correlation between ethanol oxidation currents and X-ray absorption data reveals the importance of electronic effects in the electrocatalysis of ethanol oxidation on Pd. In addition, FTIR data show that C-ATO hybrid supports promote a decrease in the onset potential and an increase in carbonate $/ \mathrm{CO}_{2}$ production.
\end{abstract}

(C) 2017 Elsevier Inc. All rights reserved.

\section{Introduction}

Power for vehicles and portable devices could be generated with low or zero $\mathrm{CO}_{2}$ emissions using Direct Ethanol Fuel Cells (DEFC) [1], but that prospective depends essentially on developing catalysts for the ethanol oxidation reaction (EOR) substantially more active than those currently available. Numerous studies were dedicated to the search for more efficient catalysts over the last decades, mostly in acid environments and mainly involving alloying Pt with transition metals [2]. Some studies also demonstrated that transition-metal oxides as co-catalysts or supports can enhance the activity of Pt nanoparticles for the oxidation of small organic molecules in acid media [3-6]. These effects were often interpreted as associated with the presence of $\mathrm{OH}$ groups on the oxide surface [7], which would favor the bifunctional mechanism $[5,6]$. On the other hand, ligand effects can also explain enhanced activities because charge transfer between the transition-metal oxide and Pt particles would shift the Fermi level of Pt, which, in turn, could modify adsorption energies [8,9].

As development of anion-exchange membranes progressed $[10,11]$, the interest in alkaline fuel cells [12] was renewed and resulted in a rapid increase in the number of studies of the EOR in base [13-15]. Recent studies demonstrated the relevance of

\footnotetext{
* Corresponding author. Fax: +55 1633222308.

E-mail address: mercedes@iq.unesp.br (H.M. Villullas).
}

metal-support interactions on the EOR catalytic activity in alkaline medium for Pt nanoparticles on hybrid supports containing different transition-metal oxides [16]. The increased attention given to studies in alkaline environments also boosted the search for Ptfree catalysts. In particular, Pd and Pd-based catalysts were widely studied [17-20]. Although the number of published papers regarding the effects of transition-metal oxides is not as large as for Pt and Pt-based catalysts, enhancing effects of $\mathrm{TiO}_{2}$ [21-26], $\mathrm{CeO}_{2}$ [27-29] and other oxide supports [30-35] were reported for Pd.

Studies of the influence of antimony tin oxide $\left(\mathrm{Sb}_{2} \mathrm{O}_{5} / \mathrm{SnO}_{2}-\right.$ ATO) on the activity of Pt nanoparticles were carried out for alcohol oxidation [36-39] and oxygen reduction [40-42]. For Pd nanoparticles, the effect of ATO was investigated only for hydrogen peroxide reduction [43] and acid formic oxidation [44]. To best of our knowledge, neither studies regarding the impact of adding ATO to Pd nanocatalysts on ethanol oxidation nor systematic evaluations of ligand effects have been published. In this work, a comparative study of activity for ethanol oxidation was carried out on catalysts having the same loading of identical Pd nanoparticles supported on carbon-oxide hybrids containing different amounts (20-40 wt.\%) of antimony tin oxide. In addition, X-ray absorption spectroscopy (XAS) experiments were carried out around the Pd $\mathrm{L}_{3}$ edge to assess the way in which interactions between metal nanoparticles and C-ATO hybrids perturb the Pd d band and in situ FTIR experiments were performed to analyze adsorbed ethanol oxidation reaction intermediates and products. 


\section{Experimental}

\subsection{Preparation of supports and catalysts}

Hybrid supports contained carbon (Vulcan XC-72, Cabot Corp.) and varying amounts of commercial antimony tin oxide nanopowder (Aldrich, $\mathrm{Sb}_{2} \mathrm{O}_{5} / \mathrm{SnO}_{2}$ - ATO; 7-11\% $\mathrm{Sb}_{2} \mathrm{O}_{5}$, particle size $<50 \mathrm{~nm}$ ). Carbon and ATO nanopowders were separately dispersed in isopropanol, keeping the mixtures in an ultrasonic bath for 10 min. The suspensions were then mixed to obtain the C-ATO hybrids, which were prepared with 20,30 and 40 wt.\% oxide content.

Pd nanoparticles were prepared in a liquid two-phase system [45] modified by the addition of oleic acid and oleylamine as capping agents. Briefly, $6.26 \mathrm{~mL}$ of aqueous solution of $\mathrm{PdCl}_{2}(0.03 \mathrm{M})$ was added to a solution of a phase-transfer agent (tetraoctylammonium bromide - ToABr) in toluene $(0.4562 \mathrm{~g}$ of $\mathrm{ToABr}$ in $16.7 \mathrm{~mL}$ of toluene). Thus, the ratio $\mathrm{ToABr} /$ metal was $4.4 / 1$. After stirring for $2 \mathrm{~h}$, the aqueous phase was separated from the toluene phase and discarded. Then, the capping agents were added $(50 \mu \mathrm{L}$ of oleic acid and $54 \mu \mathrm{L}$ of oleylamine). To reduce the $\mathrm{Pd}^{2+}$ ions, $9.4 \mathrm{~mL}$ of $0.2 \mathrm{M}$ solution of $\mathrm{NaBH}_{4}$ was slowly added (10/1 final reducer/metal ratio). After that, the system was stirred for $12 \mathrm{~h}$. At the end of this process, the toluene phase contains the Pd colloidal particles, the compound used to transfer the Pd ions from the aqueous to the organic phase (ToABr) and reducer residues. Therefore, after obtaining the Pd particles the toluene phase was washed with dilute solution of $\mathrm{H}_{2} \mathrm{SO}_{4}(5 \mathrm{mM})$, dilute solution of $\mathrm{KOH}(5 \mathrm{mM})$ and ultrapure water. Because surface properties as well as electronic effects are important in electrocatalysis [46], in order to evaluate the influence of the support on EOR activity it is indispensable to warrant that the only difference between catalysts is the support. Therefore, to prepare catalysts with identical Pd nanoparticles, each support was mixed with one fraction of the same Pd colloidal suspension. The main steps of the preparation procedure are depicted schematically in Fig. 1.

After adding the supports to the different portions of colloidal Pd nanoparticles, the resulting mixtures were stirred during $12 \mathrm{~h}$ and then the powders were filtered, and washed exhaustively with ethanol, acetone, toluene, and chloroform. The washing steps with ethanol and acetone allow removing traces of $\mathrm{ToABr}$ and reducer that might have remained in the toluene phase and remove, at

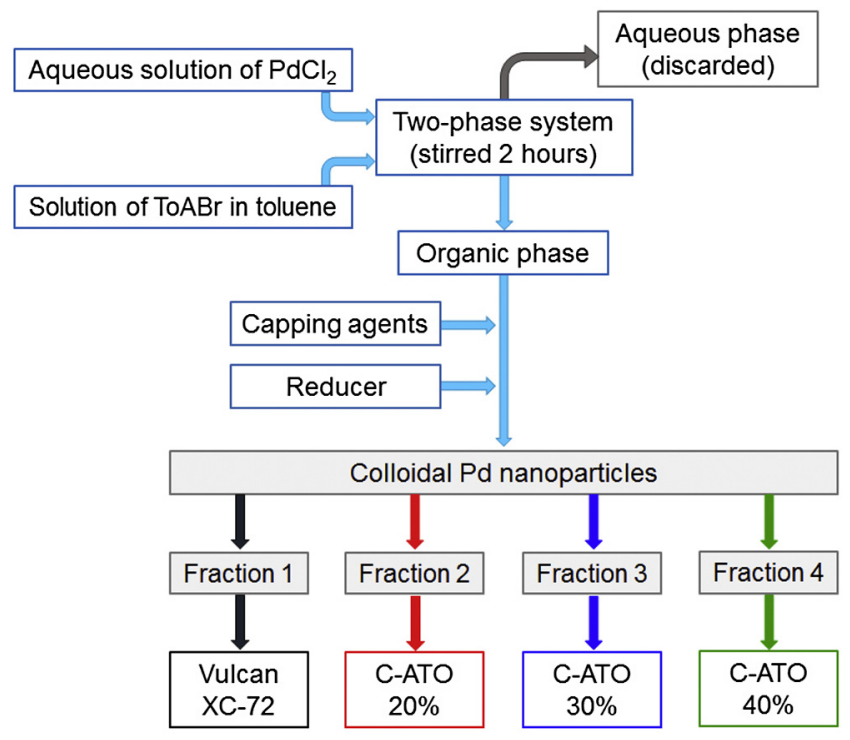

Fig. 1. Scheme of main steps of catalysts preparation procedure. least partially, the capping agents. The two following washings (one with toluene and another with chloroform) were done aiming to further remove the capping agents, as oleic acid and oleylamine are both highly soluble in these solvents [47]. After this sequence of washing steps, the filtered catalyst powder was dispersed in dilute solution of $\mathrm{KOH}$ in ethanol $(5 \mathrm{mM})$, and this dispersion kept in an ultrasonic bath for $40 \mathrm{~min}$. After filtering again, the final step of the cleaning procedure involved thoroughly washing the catalyst powder with ethanol, acetone and water. All materials were dried at $70^{\circ} \mathrm{C}$ in air. For simplicity, we shall refer to the catalysts as $\mathrm{Pd} / \mathrm{C}$-ATO (wt.\%). A Pd/C reference sample was prepared with one of the fractions of the same Pd colloid used to prepare $\mathrm{Pd} / \mathrm{C}$ ATO materials. All catalysts were prepared with 20 wt.\% Pd loading. Chemicals were purchased from Sigma-Aldrich, and used as received.

\subsection{Catalyst characterization}

X-ray diffraction measurements were carried out in a Rigaku DMax 2500 PC equipment at $2^{\circ} \mathrm{min}^{-1}$ in the $2 \theta$ range $20-100$ using $\mathrm{Cu} \mathrm{K} \alpha$ radiation $(\lambda=1.5406 \AA)$. Data were also collected in step scan mode $\left(0.02^{\circ}\right.$ step and $\left.5 \mathrm{~s} / \mathrm{step}\right)$ in the $2 \theta$ range $60-80$. Transmission electron microscopy in scanning mode (STEM) was performed with a FEI TECNAI G ${ }^{2}$ F20 HRTEM instrument.

The electronic properties were studied by X-ray absorption spectroscopy (XAS) around the $\mathrm{Pd}_{3}$ edge $(3.173 \mathrm{eV})$ at the Soft X-ray Spectroscopy (SXS) beamline of the Brazilian Synchrotron Light Laboratory (LNLS). For these measurements, the dried catalyst powder was adhered on a double-sided carbon tape fixed on an aluminum holder. Experiments were carried out in a highvacuum chamber using a InSb(111) monochromator. Photon energies were calibrated using a Mo foil and spectra were collected in total electron yield mode (TEY), with resolution of $2.2 \mathrm{eV}$. Spectra were taken on three different points of each sample.

\subsection{Electrochemistry}

Measurements were performed in a three-electrode cell, with a reversible hydrogen reference electrode (RHE) and a platinized Pt wire auxiliary electrode in a separate compartment. The working electrode was an ultra-thin layer of catalyst $\left(28 \mu \mathrm{g} \mathrm{cm}^{-2}\right.$ Pd loading) obtained depositing $10 \mu \mathrm{L}$ of catalysts ink on a previously polished glassy carbon disk $\left(0.196 \mathrm{~cm}^{2}\right.$ area). The ink was prepared dispersing $2.9 \mathrm{mg}$ of catalyst in $1 \mathrm{~mL}$ of isopropyl alcohol and $15 \mu \mathrm{L}$ of Nafion solution (5 wt.\% in a mixture of lower aliphatic alcohols and water). The Pd electrochemically active surface area was evaluated from the charge of $\mathrm{PdO}$ reduction determined from cyclic voltammetry (CV) curves measured in $0.5 \mathrm{M} \mathrm{H}_{2} \mathrm{SO}_{4}$. Experiments done for different high potential limits allow establishing the potential at which a full monolayer of PdO was completed $[48,49]$. All other CV experiments were made in alkaline medium (argon-saturated $0.1 \mathrm{M} \mathrm{KOH}$ ). Chronoamperometry (CA) curves were measured in deoxygenated $0.5 \mathrm{M}$ ethanol in $0.1 \mathrm{M} \mathrm{KOH}$ solution. All experiments were performed at $25^{\circ} \mathrm{C}$.

\subsection{In situ FTIR}

In situ multi-stepped FTIR spectroscopy experiments [50] were performed in a three-electrode spectroelectrochemical cell with a $\mathrm{CaF}_{2}$ window and using a Nicolet 6700 infrared spectrometer. The catalyst ink was deposited on a previously polished Au disk ( $8 \mu \mathrm{g} \mathrm{cm}^{-2}$ Pd loading), which was pressed against the optical window to form the thin-layer of electrolyte. A gold foil was used as counter-electrode and a reversible hydrogen electrode as reference electrode. The base spectrum was collected at $0.050 \mathrm{~V}$. Data are 
presented in terms of the reflectivity relative change $(\Delta R / R)$ obtained as follows:

$\frac{\Delta R}{R}=\frac{R_{\mathrm{ES}}-R_{\mathrm{EB}}}{R_{\mathrm{EB}}}$

where $R_{\mathrm{ES}}$ is the spectrum collected for the sample at the potential (ES) and $R_{\mathrm{EB}}$ is the spectrum collected at the base potential (EB).

\section{Results and discussion}

\subsection{Catalyst properties}

Because fractions of the same Pd colloid were used to prepare all catalysts, X-ray diffraction (XRD) analysis to estimate Pd crystallite size and lattice constant was performed for the $\mathrm{Pd} / \mathrm{C}$ sample, thus avoiding interference of $\mathrm{Sb}_{2} \mathrm{O}_{5}$ and $\mathrm{SnO}_{2}$ signals. The diffraction pattern is shown in Fig. 2a, which exhibits the typical diffraction signals of the face centered cubic (fcc) Pd structure (PDF 87$643)$. The [220] diffraction peak was fitted with a pseudo-Voigt function (Fig. 2b) and used for calculations taking advantage of the absence of carbon signals in that $2 \theta$ region. The mean crystallite diameter was estimated using Scherrer's equation as being $2.2 \mathrm{~nm}$. The apparent lattice constant was found to be $3.901 \AA$, which is slightly larger than the value for Pd metal (3.890 ̊). Variation of lattice parameters with nanoparticle size, which can be explained in terms of strain [51], has been reported for oxides [52] and pure metals such as Ag, Au and Pt [53,54], and is commonly found in the literature for Pd and Pd-based alloys [55,56]. Recently, Ohba et al. [57] investigated the expansion of the Pd lattice as particle size decreases by EXAFS (extended X-ray absorption fine structure) and observed that the Pd-Pd distance in small particles ( $<3 \mathrm{~nm}$ diameter) was larger by $2 \%$ than for Pd foil.

Scanning Transmission Electron Microscopy (STEM) analysis showed small Pd nanoparticles well distributed on the supports. Fig. 3a and b depicts a typical STEM bright field image for Pd/C and the size distribution histogram. Average particle size was found to be $3.3 \pm 0.2 \mathrm{~nm}$. These analyses also showed the presence of Pd nanoparticles on the oxide component of the hybrid supports, as shown in the bright and dark field images of Fig. $3 \mathrm{c}$ and $\mathrm{d}$.

X-ray absorption spectroscopy (XAS) allows probing the electronic structure of states above the Fermi level. In the case of transition metals, the absorption of X-rays promotes the excitation of $2 p$ electrons to unfilled d orbitals ( $4 \mathrm{~d}$ for transition metals of the second row, such as Pd) that results in an absorption peak called absorption edge. In this work, measurements were performed

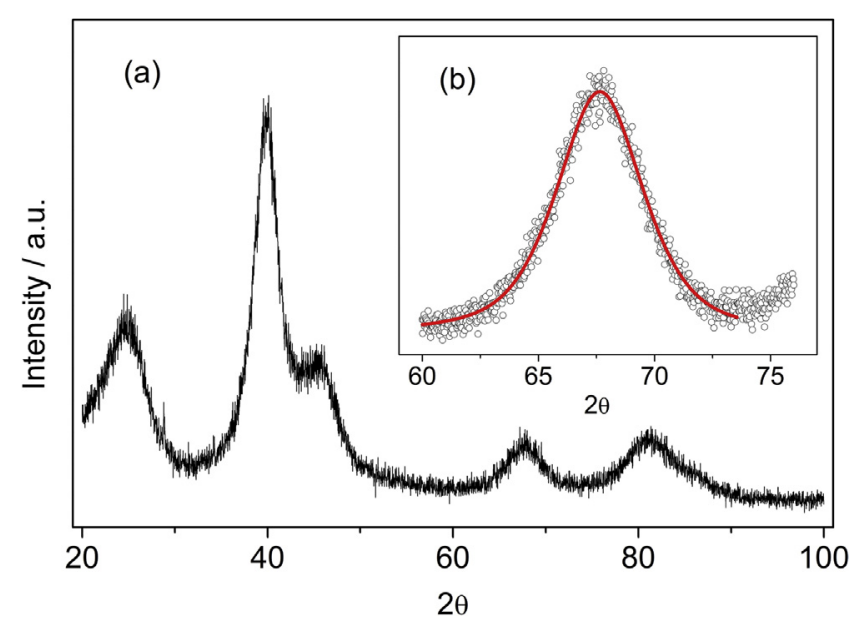

Fig. 2. (a) X-ray diffractogram of carbon-supported Pd nanoparticles. (b) Fitting with a pseudo-Voigt function of the [200] signal. around the $\mathrm{Pd} \mathrm{L}_{3}$ edge ( $3.173 \mathrm{eV}, 2 \mathrm{p}_{3 / 2} \rightarrow \mathrm{d}$ transitions). All spectra were normalized with the ATHENA program [58]. Fig. 4a shows a comparison of normalized X-ray absorption spectra collected on three different points of the $\mathrm{Pd} / \mathrm{C}-\mathrm{ATO}(30)$ sample (absorption maximum expanded in the inset). Similar reproducibility was obtained for all materials. XAS data for Pd on hybrid supports with different amounts of ATO are compared in Fig. 4b, where the inset shows the absorption peak region enlarged. The XANES (X-ray Absorption Near Edge Structure) region was analyzed as proposed by Shukla et al. [59], i.e., by fitting the absorption spectrum with a Lorentzian curve that represents transitions to bound states combined with an arc tangent curve to account for transitions to the continuum. Integration of the fitted Lorentzian curve enables a quantitative comparison of the electronic occupancy of the Pd $4 d$ band (smaller values of the integral indicate a larger electronic occupancy [60]). In consequence, comparison of the values of the integral of the Lorentzian curve allows assessing the effect of the C-ATO supports on the Pd electronic properties. Results shown in Fig. 4c clearly evidence that the electronic occupancy of the Pd 4d band is larger for Pd/C-ATO catalysts than for Pd/C, and follows the amount of ATO in the hybrid support. It is important to remember that catalysts were prepared with identical Pd particles and equal Pd loading, so the changes in electronic properties can only be associated with the differences in the supports. In other words, data reveal an electronic transfer from the hybrid support to the Pd particles indicating that the interactions between the metal nanoparticles and the C-ATO supports promote a shift in the Pd d-band center [61].

\subsection{Electrochemistry and catalytic activity for EOR}

The charge of PdO reduction obtained from CV curves was used to evaluate the electrochemically active area of Pd. Clearly, the electrochemically active area of Pd does not depend on the electrolyte in which it is determined. Therefore, these experiments were performed in argon-saturated $0.5 \mathrm{M} \mathrm{H}_{2} \mathrm{SO}_{4}$ because the procedure is very well established for acid solutions [48], where the oxidation/reduction processes are better defined than in alkaline environments. To determine the potential corresponding to the completion of a PdO monolayer CV curves were measured between $0.40 \mathrm{~V}$ and a high potential limit varied from 1.20 to $1.55 \mathrm{~V}$ (Fig. 5a). To avoid accumulative charge losses due to Pd dissolution, the $\mathrm{CV}$ for each different potential limit was measured on a fresh ultra-thin layer of catalyst. It should be noted that the excellent correlation of the CV curves shown in Fig. 5a also demonstrates the good reproducibility of the preparation of the catalyst layer. It is worth to point out that the presence of ATO $\left(\mathrm{Sb}_{2} \mathrm{O}_{5} / \mathrm{SnO}_{2}\right)$ in the support only contributes to the double-layer charging as shown in Supplementary Fig. 1. The change in slope in the plot of the reduction charge $\left(Q_{R}\right)$ against the high potential limit (Fig. 5b) occurs at $1.45 \mathrm{~V}$ in agreement with the literature [49]. Pd areas were calculated using $424 \mu \mathrm{C} \mathrm{cm}^{-2}$ as reduction charge density of a PdO monolayer [48]. The Pd area exposed to the electrolyte was found to be $4.3 \mathrm{~cm}^{2}$ for Pd/C, while for Pd/C-ATO catalysts the Pd areas were $4.4,4.2$ and $3.9 \mathrm{~cm}^{2}$ for supports with 20,30 and $40 \mathrm{wt} . \%$ ATO, respectively.

The CV curves taken in argon-saturated $0.1 \mathrm{M} \mathrm{KOH}$ solution, depicted in Fig. 6a show the same general shape and no significant differences in current, as expected from the similar Pd electrochemically active areas. CV curves recorded in solution containing ethanol indicate that Pd/C-ATO catalysts are more active toward the EOR than Pd/C (Fig. 6b). It should be kept in mind, however, that the current measured under potentiodynamic conditions includes the unknown contribution of double layer charging, which depends on the total (metal + support) surface area and on the applied potential. Hence, the electroactivity of different cata- 


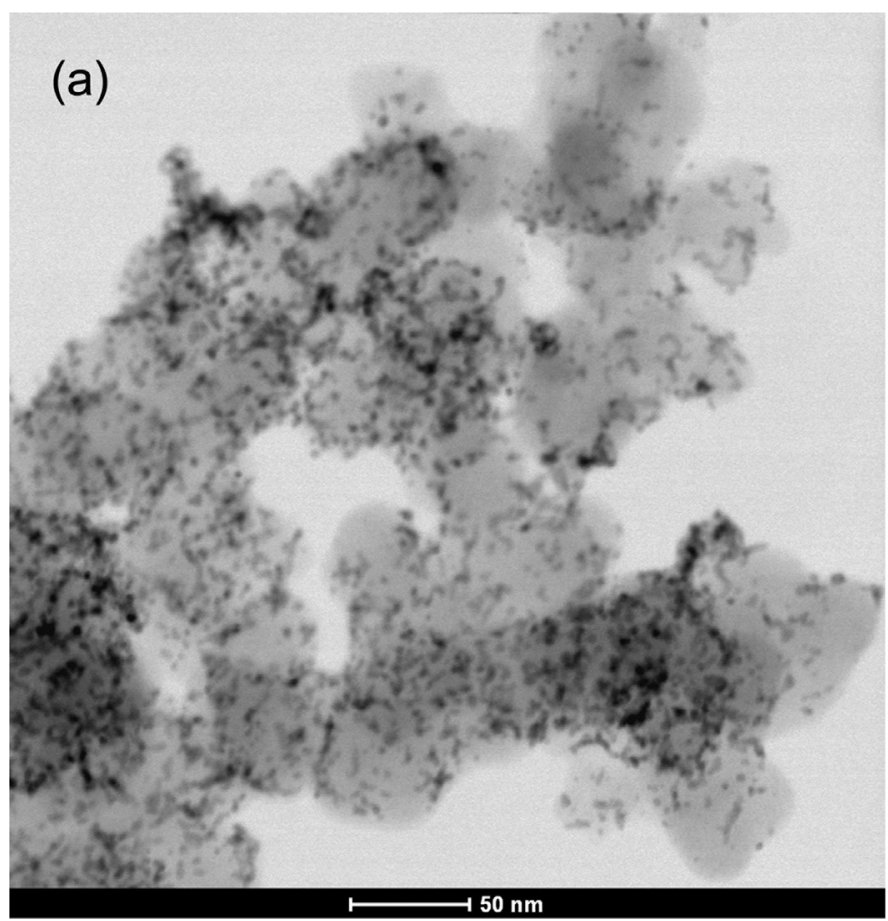

(b)
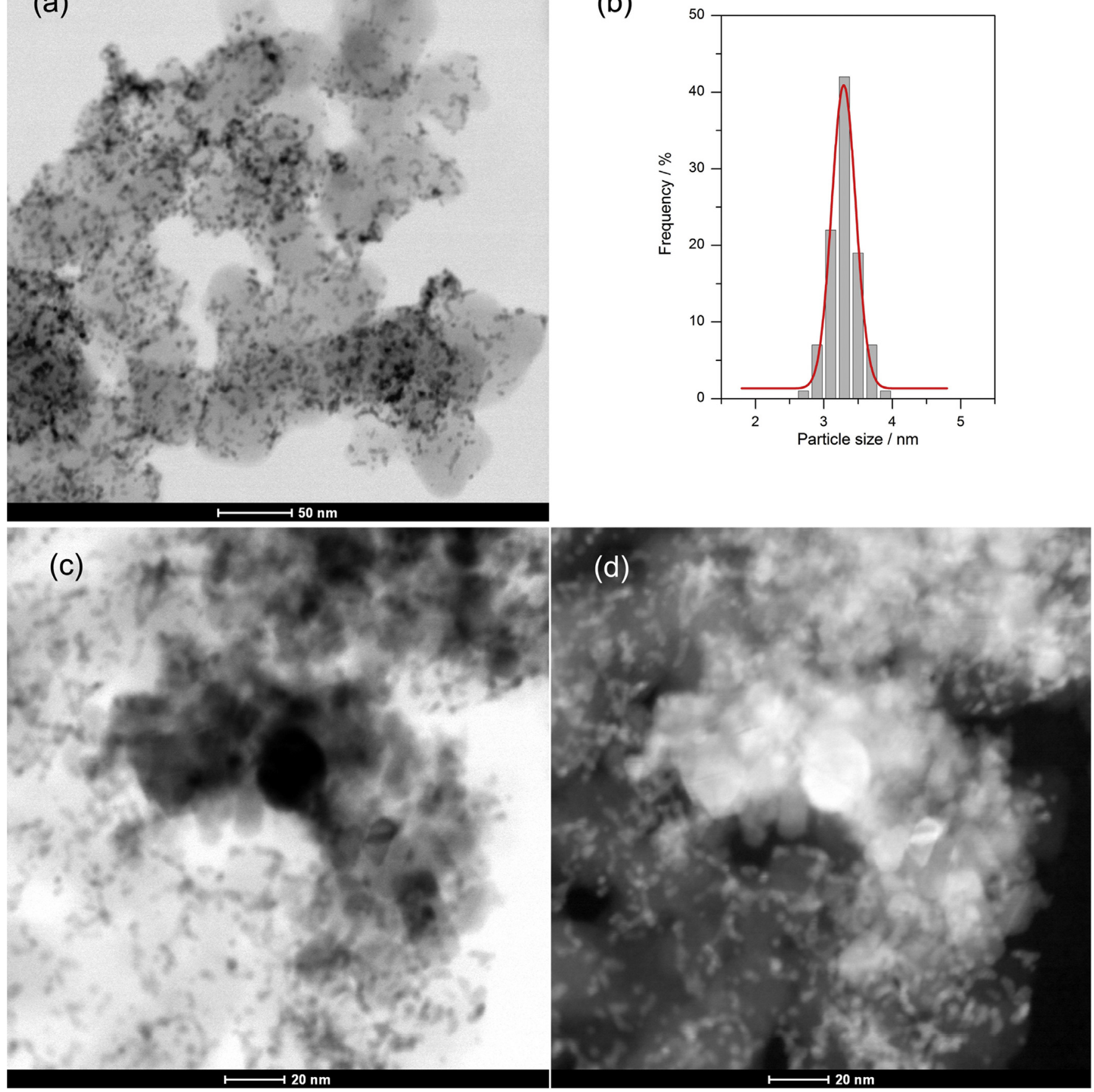

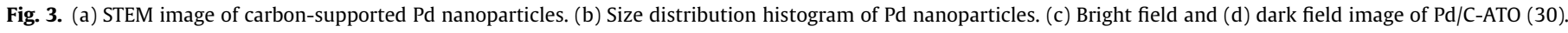

lysts was assessed from the ethanol oxidation current density from chronoamperometry experiments.

CA curves measured at constant applied potential of $0.60 \mathrm{~V}$ are presented in Fig. 7a, where the current was normalized by the Pd active area. Clearly, EOR current densities are higher on $\mathrm{Pd} / \mathrm{C}$ ATO than on Pd/C. Furthermore, the EOR activity is higher as the content of ATO in the support increases. The inset in Fig. 7a shows a comparison of EOR current densities after $40 \mathrm{~min}$ of polarization. A plot of the current density against the integral of the Lorentzian curves fitted to XAS spectra (Fig. 4c) is presented in Fig. 7b. The strong correlation between EOR current density and band occu- pancy unveils the relevance of electronic effects. It is worth to remember here that smaller values of the integral of the Lorentzian curve indicate a larger electronic occupancy of the Pd $4 \mathrm{~d}$ band (i.e., larger electronic transfer from the support to the metal). Indeed, data of Fig. 7b show that the increase in the electronic occupancy of the Pd $4 \mathrm{~d}$ band results in an enhancement of EOR activity.

It is important to note that the Pd $4 \mathrm{~d}$ band is the relevant one regarding chemisorption and, thus, changes in its electronic occupancy might alter the energies of adsorption. In the case of EOR, the first reaction step is the adsorption ethanol (either through the carbon atom or through the oxygen atom [62,63]). Besides that, 

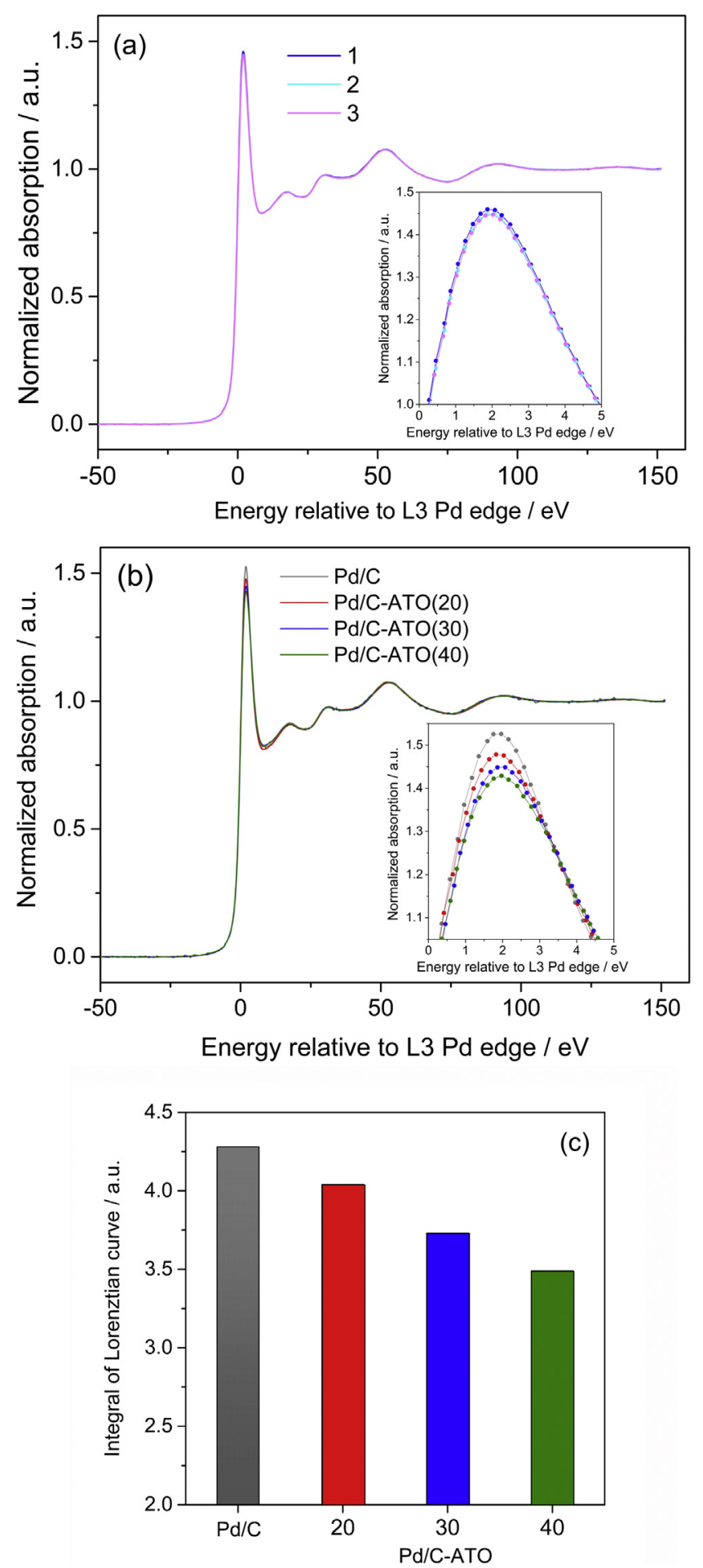

Fig. 4. (a) Normalized X-ray absorption spectra collected on different points of the $\mathrm{Pd} / \mathrm{C}$ sample. Inset: absorption peak region enlarged. (b) Normalized X-ray absorption spectra of $\mathrm{Pd} / \mathrm{C}-\mathrm{ATO}$ and $\mathrm{Pd} / \mathrm{C}$ catalyst. Inset: absorption peak region enlarged. (c) Integrals of the Lorentzian curves fitted to spectra.

chemisorption of $\mathrm{OH}$ species is needed for the oxidation reaction to proceed, which probably involves parallel pathways through which acetaldehyde and acetate would be formed [15,63].

A clear correlation between EOR activity in alkaline solution and electronic properties was recently reported for Pt nanoparticles supported on C-oxide hybrids containing different transitionmetal oxides [16]. It was found that the EOR on Pt was enhanced on those catalysts that have a larger Pt $5 \mathrm{~d}$ band electronic vacancy.
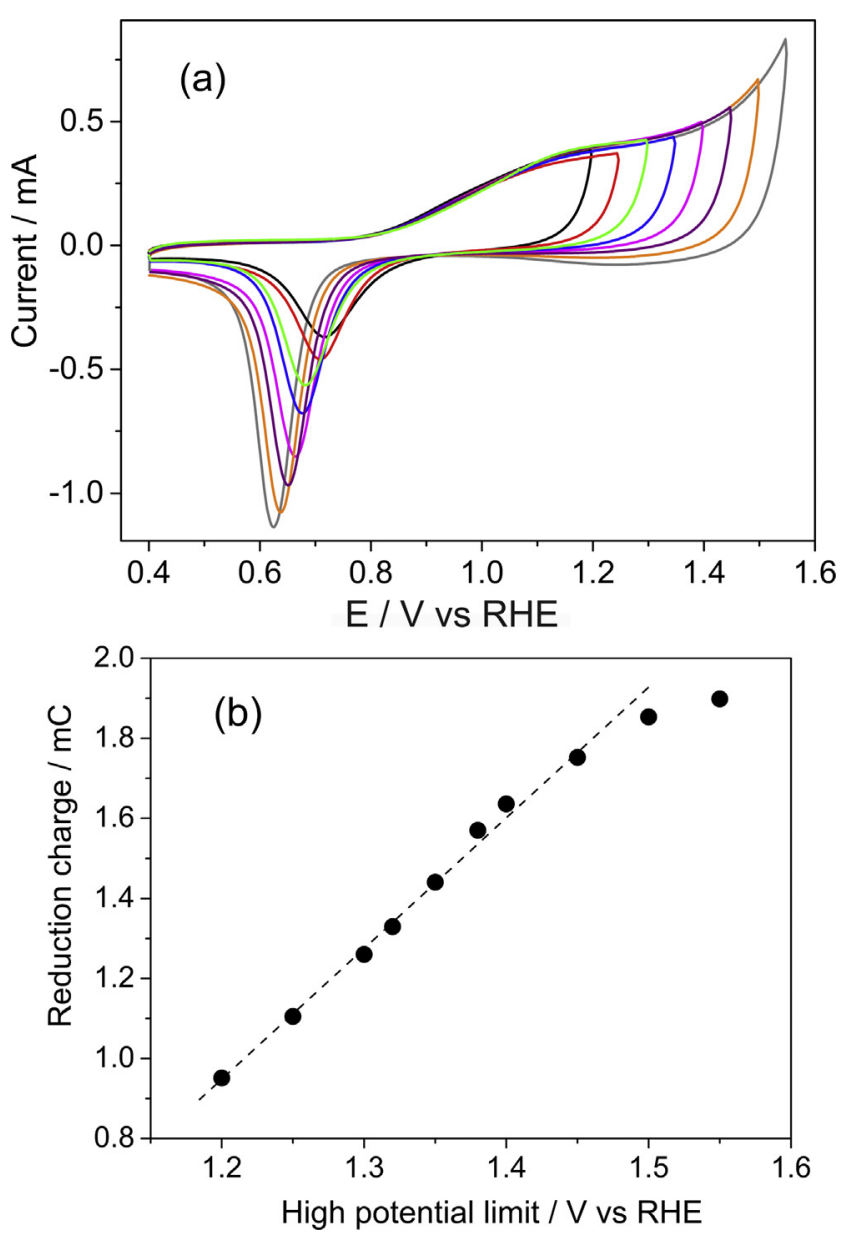

Fig. 5. (a) CVs of $\mathrm{Pd} / \mathrm{C}$ at $50 \mathrm{mV} \mathrm{s}^{-1}$ measured between $0.4 \mathrm{~V}$ and different high potential limits (1.20-1.55 V) in argon-saturated $0.5 \mathrm{M} \mathrm{H}_{2} \mathrm{SO}_{4}$ (first cycles). (b) PdO reduction charge $\left(Q_{R}\right)$ against high potential limit.

In other words, while data for Pt demonstrated that EOR enhancement was promoted by a $5 \mathrm{~d}$ band more empty [16], the results for Pd reported here show that activity increases as the $4 \mathrm{~d}$ band is more filled. This suggests that electronic effects might have dissimilar consequences on EOR activity on different active metals. In fact, chemisorption energies are not expected to be the same on Pd than on Pt and thus, a dissimilar impact of the metal electronic structure on different reaction pathways would not be unlikely.

Aiming to gain some further insight into the differences on catalytic activities toward ethanol oxidation, in situ FTIR spectra were measured between 0.05 and $1.0 \mathrm{~V}$ in $0.5 \mathrm{M}$ ethanol in $0.1 \mathrm{M} \mathrm{KOH}$ solution for $\mathrm{Pd} / \mathrm{C}-\mathrm{ATO}(40)$, which exhibits the best performance, and for the $\mathrm{Pd} / \mathrm{C}$ reference sample (Fig. 8).

The two loss bands (upward) observed at 1085 and $1045 \mathrm{~cm}^{-1}$ are attributed to the diminution of the amount of ethanol in the thin layer of electrolyte while the gain bands (downward) at 1550 and $1415 \mathrm{~cm}^{-1}$ are assigned to acetate $\left(\mathrm{COO}^{-}\right.$symmetric and asymmetric stretching, respectively). All these features due to ethanol oxidation start to appear in the spectra of Pd/C-ATO (40) at about $0.3 \mathrm{~V}$ but they are not observable for $\mathrm{Pd} / \mathrm{C}$ until higher applied potentials, suggesting a lower onset potential of ethanol oxidation for Pd/C-ATO(40).

The main reactions involved in ethanol oxidation in alkaline solution are the partial oxidation to acetate and the complete oxidation to $\mathrm{CO}_{2}$, which can be written as follows:

$\mathrm{CH}_{3} \mathrm{CH}_{2} \mathrm{OH}+5 \mathrm{OH}^{-} \rightarrow \mathrm{CH}_{3} \mathrm{COO}^{-}+4 \mathrm{H}_{2} \mathrm{O}+4 \mathrm{e}$ 

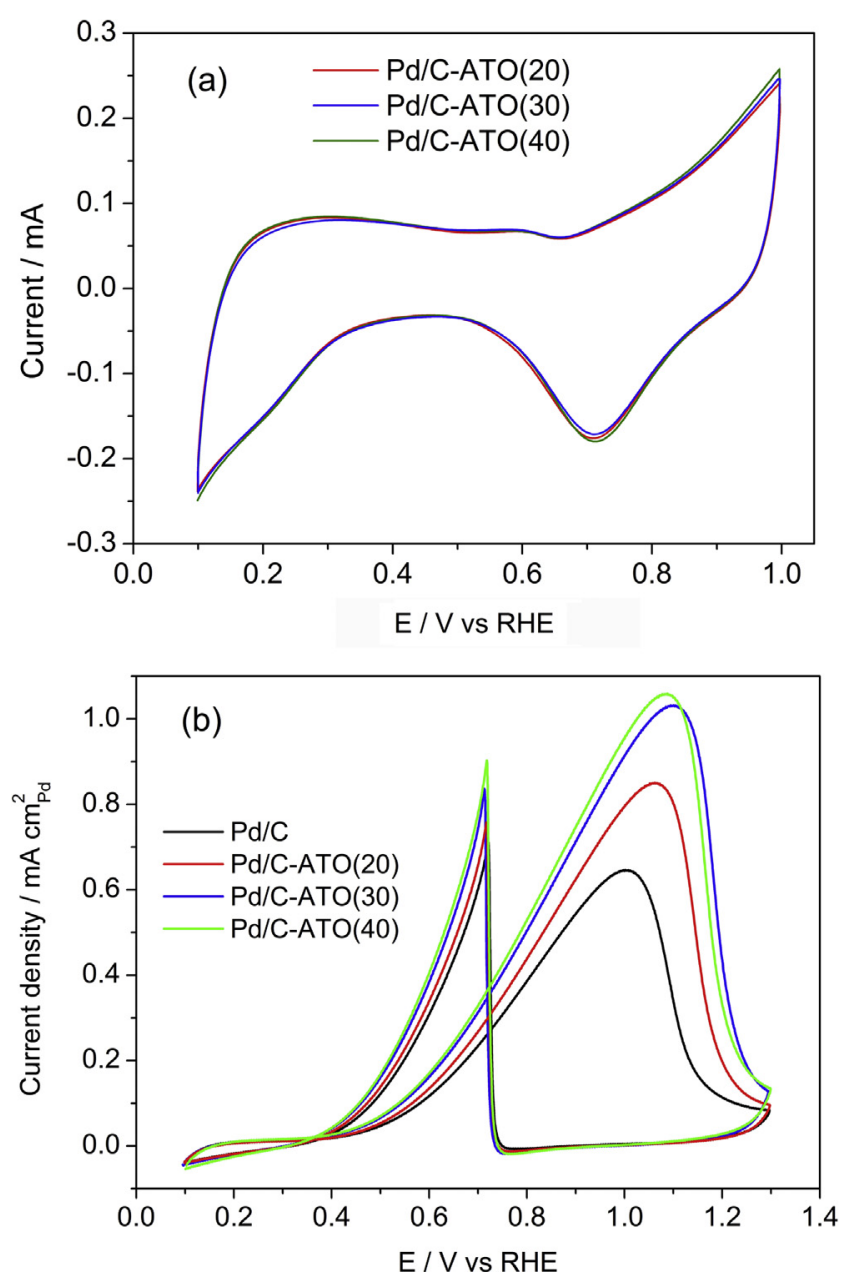

Fig. 6. (a) Cyclic voltammetry curves for Pd/C-ATO catalysts taken in argonsaturated $0.1 \mathrm{M} \mathrm{KOH}$ solution at $50 \mathrm{mV} \mathrm{s}^{-1}$. (b) Comparison of cyclic voltammetry curves (first cycles) taken in $0.5 \mathrm{M}$ ethanol in $0.1 \mathrm{M} \mathrm{KOH}$ solution at $10 \mathrm{mV} \mathrm{s}^{-1}$.

$\mathrm{CH}_{3} \mathrm{CH}_{2} \mathrm{OH}+12 \mathrm{OH}^{-} \rightarrow 2 \mathrm{CO}_{2}+9 \mathrm{H}_{2} \mathrm{O}+12 \mathrm{e}$

$\mathrm{CO}_{2}+2 \mathrm{OH}^{-} \rightarrow \mathrm{CO}_{3}^{2-}+\mathrm{H}_{2} \mathrm{O}$

At potentials above $0.6 \mathrm{~V}$ the formation of $\mathrm{CO}_{2}$ on the $\mathrm{Pd} / \mathrm{C}-\mathrm{ATO}$ catalyst due to the acidification of the thin layer of electrolyte is evidenced by the band at $2343 \mathrm{~cm}^{-1}$, which is not observed for the $\mathrm{Pd} / \mathrm{C}$ sample. The fact that no $\mathrm{CO}_{2}$ band is apparent for the carbon-supported catalyst is in agreement with the FTIR data reported for Pd black by Zhou et al. [64]. Spectra of Fig. 8 also show that signals that would indicate formation of linearly bonded $\mathrm{CO}$ (2055-2060 $\left.\mathrm{cm}^{-1}\right)$ [62] are not observed.

As mentioned above, for these measurements a thin catalyst layer was deposited on a polished gold disk. Even though $\mathrm{Au}$ is active for ethanol oxidation [65], its contribution is negligible in the conditions of our FTIR experiments. A comparison of CV curves taken in a conventional three-electrode cell is presented in Supplementary Fig. 2, and demonstrates that the current of ethanol oxidation on the Au substrate is negligible at least up to $0.9 \mathrm{~V}$, where the current on the bare Au disk is about $1.5 \%$ of that measured for the $\mathrm{Pd} / \mathrm{C}$ catalyst layer. Therefore, we must analyze whether a substrate contribution might be of significance for the spectra taken at $1.0 \mathrm{~V}$. For that analysis, we have to keep in mind that during FTIR experiments the thin layer of electrolyte formed between the optical window and the working electrode becomes more acidic because the EOR occurs with $\mathrm{OH}^{-}$consumption. On the other hand,
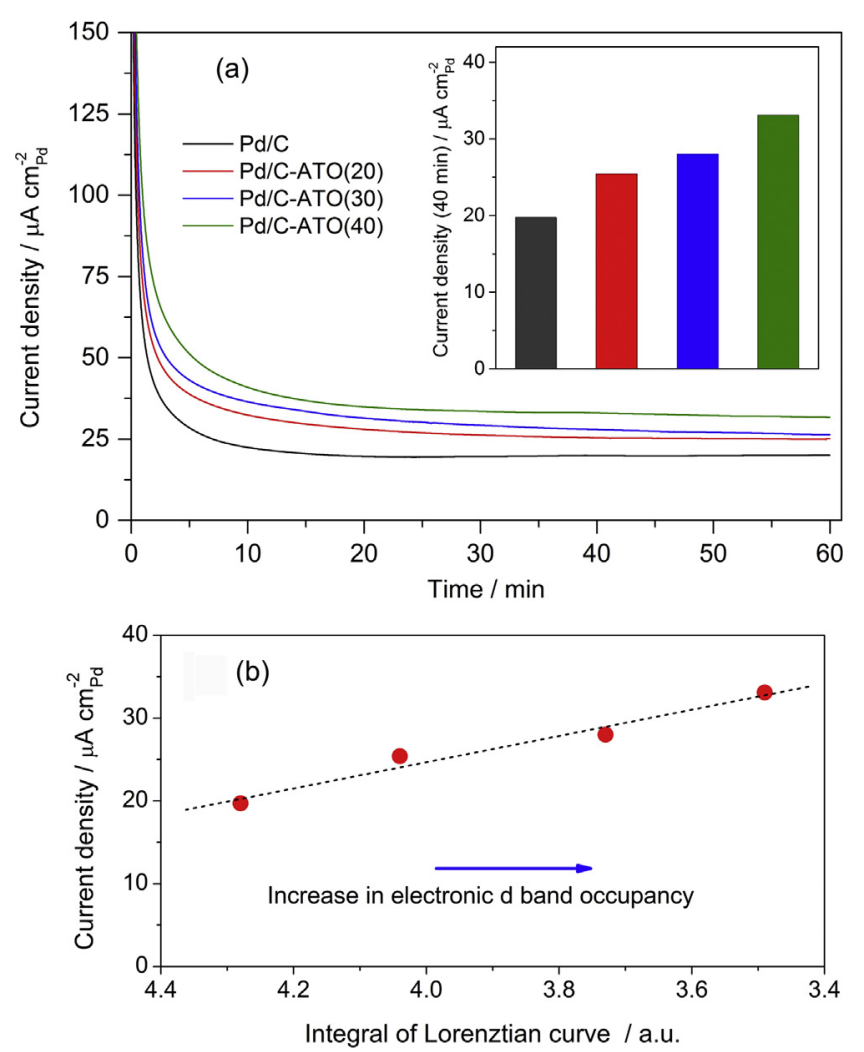

Fig. 7. (a) Ethanol oxidation current densities at $0.60 \mathrm{~V}$. Inset: current density after 40 min polarization. (b) Current density against the integral values of the Lorentzian curves of Fig. 4c.

we must remember that the activity of Au decreases sharply as the $\mathrm{pH}$ of electrolyte diminishes [15] and, thus, it is reasonable to consider that the contribution of the Au disk will be significantly smaller in the FTIR spectra taken at $1.0 \mathrm{~V}$ than in the CV experiments done in a conventional electrochemical cell. In other words, even for the spectra taken at $1.0 \mathrm{~V}$ the contribution of the Au substrate would not be significant.

Further analysis of the spectra of Fig. 8 shows that a gain band due to carbonate formation (c.a. $1390 \mathrm{~cm}^{-1}$ ) is not apparent most likely because of its close proximity to the acetate band at $1415 \mathrm{~cm}^{-1}$. However, the formation of $\mathrm{CO}_{3}^{2-}$ can be inferred from the comparison of the intensities of the bands at 1550 (B1) and 1415 (B2) $\mathrm{cm}^{-1}$ in the spectra collected at different potentials, that vary differently for $\mathrm{Pd} / \mathrm{C}-\mathrm{ATO}(40)$ and $\mathrm{Pd} / \mathrm{C}$. An alternative way to follow the formation of $\mathrm{CO}_{3}^{2-}$ and its conversion to $\mathrm{CO}_{2}$ as potential is increased consists in subtracting from the spectrum collected to a given potential $\left(E_{i}\right)$ the one collected at the previous one $\left(E_{i-1}\right)$, as the resulting spectrum would evidence the main changes that took place when the applied potential was increased in $0.1 \mathrm{~V}$. The results obtained for Pd/C-ATO(40) and Pd/C are depicted in Fig. 9.

In the case of $\mathrm{Pd} / \mathrm{C}-\mathrm{ATO}(40)$ (Fig. 9a), a loss signal at about $1390 \mathrm{~cm}^{-1}$ is clearly seen in the spectrum resulting from subtracting from the spectrum collected at $0.6 \mathrm{~V}$ the one measured at $0.5 \mathrm{~V}$. This feature is more pronounced in the next spectrum $\left(E_{i}-E_{i 1}=0.7-\right.$ $0.6)$, where the appearance of a small $\mathrm{CO}_{2}$ band is also observed. For higher potentials, the $\mathrm{CO}_{2}$ band increases. As ethanol oxidation continues, the $\mathrm{pH}$ in the thin layer of electrolyte decreases and bands at 1715 and $1280 \mathrm{~cm}^{-1}$ that can be attributed to acetic acid are apparent in the $E_{i}-E_{i 1}=1.0-0.9$ spectrum while the downward band of acetate at $1415 \mathrm{~cm}^{-1}$ gradually widens probably as result of the superposition with a band at $1378 \mathrm{~cm}^{-1}$ also attributed to acetic acid. In contrast, for $\mathrm{Pd} / \mathrm{C}$ (Fig. 9b) the loss feature at 
(a)

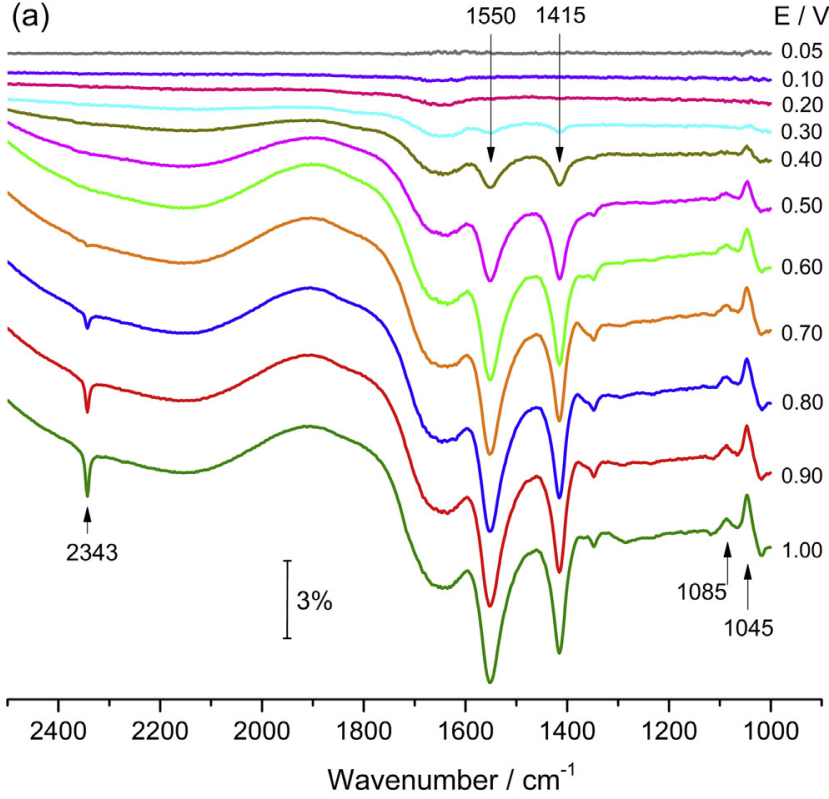

(b)

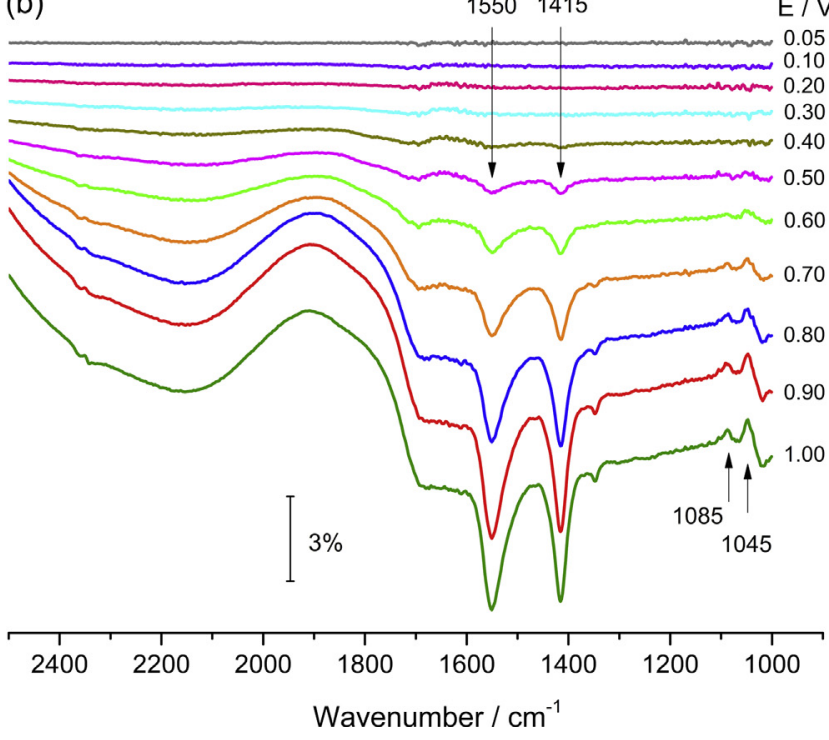

Fig. 8. In situ FTIR spectra collected at different potentials in $0.5 \mathrm{M}$ ethanol in $0.1 \mathrm{M}$ $\mathrm{KOH}$ solution. (a) Pd/C-ATO(40), (b) Pd/C. EB: $0.05 \mathrm{~V}, 100$ scans, $8 \mathrm{~cm}^{-1}$.

$1390 \mathrm{~cm}^{-1}$ is observed as a very small signal that appears only in the $E_{i}-E_{i 1}$ 0.9-0.8 spectrum while a very small $\mathrm{CO}_{2}$ band seems apparent in the following change of $0.1 \mathrm{~V}$ (spectrum $\mathrm{E}_{\mathrm{i}}-\mathrm{E}_{\mathrm{i} 1}=1.0$ $0.9)$.

While the main reactions involved in ethanol oxidation in alkaline media are those that lead to the formation of acetate and $\mathrm{CO}_{3}^{2-}$ given above, the EOR is quite complex and involves several parallel pathways. According to the reaction mechanism proposed by Lai et al. [15] the high currents observed in alkaline solutions would be mainly due to the production of larger amounts of acetaldehyde, which would be formed from adsorbed ethoxy, at the time that the main reactive species for its oxidation would be the deprotonated form of hydrated acetaldehyde $\left(\mathrm{CH}_{3} \mathrm{CHOHO}^{-}\right)$. These authors also pointed out that the most likely species in which the $\mathrm{C}-\mathrm{C}$ bond break would occur is an acetaldehyde-like intermediate.

As discussed above, our data show that the interactions between the Pd nanoparticles and C-ATO supports lead to an increase in the $\mathrm{Pd} 4 \mathrm{~d}$ band electronic occupancy and to an enhancement of the EOR current density (Figs. 4 and 7). On the (a)

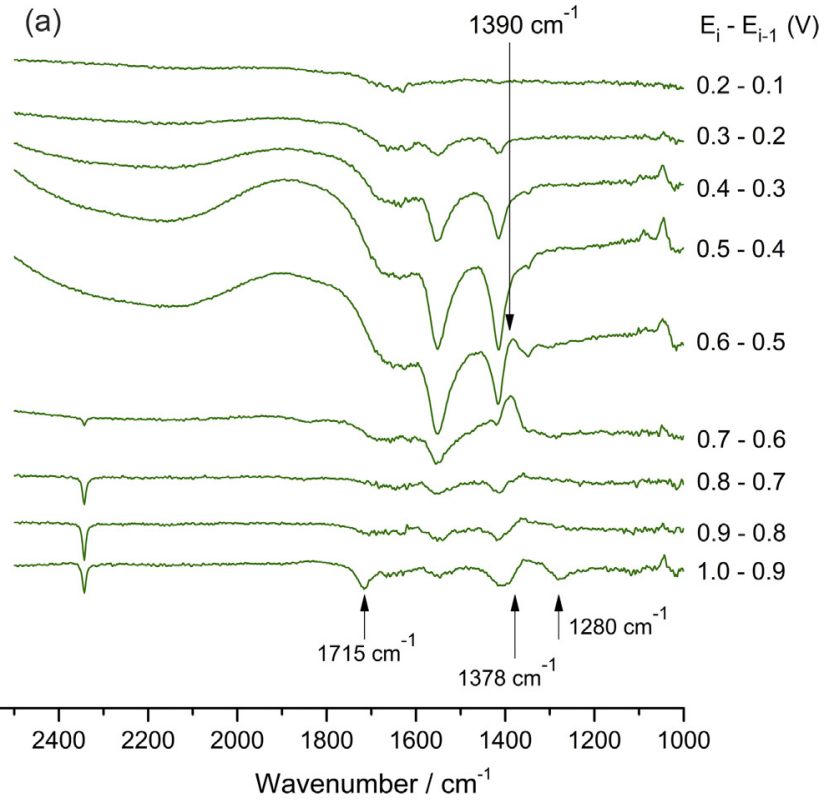

(b)

$E_{i}-E_{i-1}(V)$
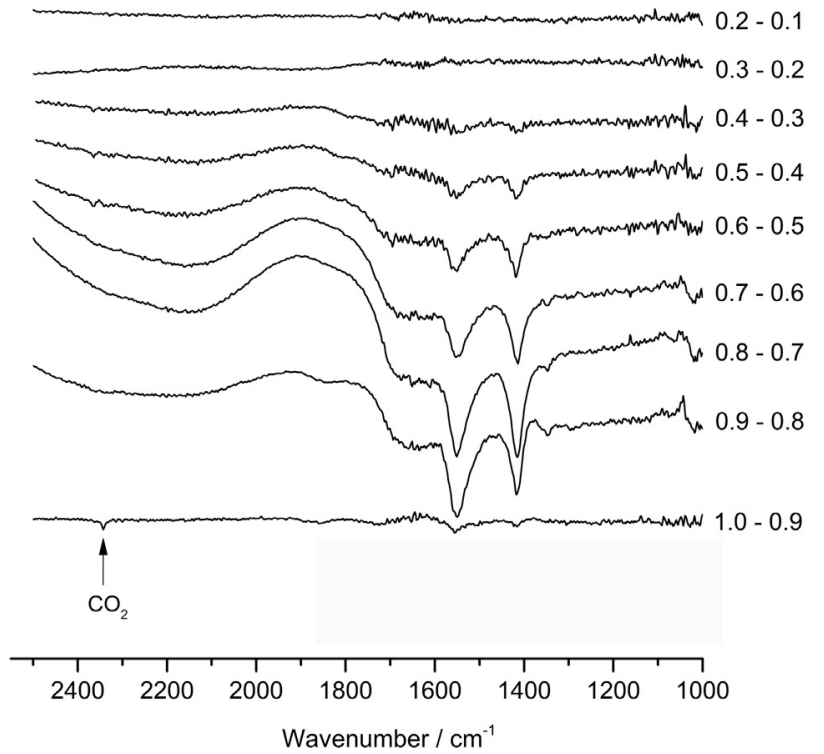

Fig. 9. Spectra obtained after subtracting the spectrum collected at potential $\left(E_{i-1}\right)$ from the one collected after increasing the potential in $0.1 \mathrm{~V}\left(\mathrm{E}_{\mathrm{i}}\right)$. (a) Pd/C-ATO(40), (b) $\mathrm{Pd} / \mathrm{C}$.

other hand, the FTIR results evidenced that also the complete oxidation of ethanol to $\mathrm{CO}_{2}$ is enhanced on the Pd/C-ATO catalyst. These results suggest that the more filled $4 \mathrm{~d}$ band of Pd would favor the formation of acetaldehyde, which would explain the higher ethanol oxidation currents and the somewhat larger extent of $\mathrm{C}-\mathrm{C}$ bond breaking promoted by C-ATO supports.

Several studies of the EOR on Pd involving the addition of oxides such as $\mathrm{TiO}_{2}$ [23-26], $\mathrm{CeO}_{2}[25,27,28]$ and other oxide supports $[30,32,33]$ were published. However, comparison of results is very difficult mainly because of the different oxides added, the differences in the amount of oxides and the support nanostructure (with or without carbon, nanotubes, etc.), and the great variations of the size of Pd nanoparticles [25]. In a general manner, higher EOR activity was usually attributed to larger amounts of oxygenated species on the support surface and/or charges in the electronic properties although experimental evidence for that was not provided. The results presented here would allow understanding some 
of the discrepancies in the literature because the nature and amount of the oxides in the catalysts are expected to influence the electronic occupancy of the $d$ band. On the other hand, it has been shown that the size of the nanoparticles may also affect the active metal electronic properties [66].

In summary, the results presented here prove quite clearly that the electronic occupancy of the Pd $4 \mathrm{~d}$ band can change as consequence of the interaction of Pd nanoparticles with carbon-oxide hybrid supports, and demonstrate that the increase in EOR currents promoted by C-ATO hybrid supports is related to ligand effects. The enhanced current, the decrease in the onset potential, and the change in the distribution of reaction products evidenced by the formation of $\mathrm{CO}_{3}^{2-}$ and $\mathrm{CO}_{2}$ at lower potentials than on $\mathrm{Pd} /$ $\mathrm{C}$ can be interpreted as result of the formation of larger amounts of acetaldehyde on the Pd/C-ATO catalyst. While the question of breaking the $\mathrm{C}-\mathrm{C}$ bond at room temperature is far from been solved, improvements could be made by tuning the electronic properties of the catalytic metal.

\section{Conclusions}

Carbon-oxide hybrids containing different amounts of antimony tin oxide (ATO) were used to support Pd nanoparticles. The observed changes in EOR activity can be unequivocally ascribed to the differences in the supports because all catalysts had the same loading of essentially identical Pd nanoparticles. X-ray absorption spectroscopy studies revealed an electronic transfer from carbon-oxide supports to Pd particles that increase the electronic occupancy of the Pd $4 \mathrm{~d}$ band. It was demonstrated that the hybrid supports studied in this work enhanced the EOR activity, which follows the increase in the $4 \mathrm{~d}$ band electronic occupancy. FTIR results show a decrease in the EOR onset potential and formation of $\mathrm{CO}_{3}^{2-} / \mathrm{CO}_{2}$ at lower potentials on Pd/C-ATO than on $\mathrm{Pd} / \mathrm{C}$. In summary, the results presented herein unveiled, for the first time, a strong correlation between electronic properties and ethanol oxidation activity on Pd nanoparticles.

\section{Acknowledgments}

This work was supported by Brazilian agencies Fundação de Amparo à Pesquisa do Estado de São Paulo (FAPESP), (2013/50206-4; 2014/12255-6), and Conselho Nacional de Desenvolvimento Científico e Tecnológico (CNPq), (407143/2013-0). Thanks are due to the Brazilian Synchrotron Light Laboratory (LNLS) for assisting XAS experiments. GMA thanks FAPESP (2014/02387-2; 2016/05041-5) and IBCG thanks CNPq (142497/2013-4) for the fellowships granted.

\section{Appendix A. Supplementary material}

Supplementary data associated with this article can be found, in the online version, at http://dx.doi.org/10.1016/j.jcat.2017.02.002.

\section{References}

[1] L. An, T.S. Zhao, Y.S. Li, Renew. Sust. Energy Rev. 50 (2015) 1462-1468.

[2] M.R. Tarasevich, O.V. Korchagin, A.V. Kuzov, Russ. Chem. Rev. 82 (2013) $1047-$ 1065.

[3] H.M. Villullas, F.I. Mattos-Costa, P.A.P. Nascente, L.O.S. Bulhoes, Electrochim. Acta 49 (2004) 3909-3916.

[4] H.M. Villullas, F.I. Mattos-Costa, P.A.P. Nascente, L.O.S. Bulhoes, Chem. Mater. 18 (2006) 5563-5570.

[5] P.J. Kulesza, I.S. Pieta, I.A. Rutkowska, A. Wadas, D. Marks, K. Klak, L. Stobinski, J.A. Cox, Electrochim. Acta 110 (2013) 474-483.

[6] Z. Zhang, J. Liu, J. Gu, L. Su, L. Cheng, Energy Environ. Sci. 7 (2014) 2535-2558.

[7] S. Trasatti, Mater. Chem. Phys. 16 (1987) 157-174.

[8] S. Kaya, D. Friebel, H. Ogasawara, T. Anniyev, A. Nilsson, J. Electron Spectrosc. Relat. Phenom. 190 (2013) 113-124.

[9] P. Liu, J.K. Norskov, Phys. Chem. Chem. Phys. 3 (2001) 3814-3818.
[10] S. Maurya, S.-H. Shin, Y. Kim, S.-H. Moon, Rsc Adv. 5 (2015) 37206-37230.

[11] J. Cheng, G. He, F. Zhang, Int. J. Hydrogen Energy 40 (2015) 7348-7360.

[12] A. Brouzgou, A. Podias, P. Tsiakaras, J. Appl. Electrochem. 43 (2013) 119-136.

[13] Y. Wang, S.Z. Zou, W.B. Cai, Catalysts 5 (2015) 1507-1534.

[14] S.C.S. Lai, M.T.M. Koper, Phys. Chem. Chem. Phys. 11 (2009) 10446-10456.

[15] S.C.S. Lai, S.E.F. Kleijn, F.T.Z. Ozturk, V.C.V. Vellinga, J. Koning, P. Rodriguez, M.T. M. Koper, Catal. Today 154 (2010) 92-104.

[16] D.R.M. Godoi, H.M. Villullas, F.-C. Zhu, Y.-X. Jiang, S.-G. Sun, J. Guo, L. Sun, R. Chen, J. Power Sources 311 (2016) 81-90.

[17] L. Wang, A. Lavacchi, M. Bevilacqua, M. Bellini, P. Fornasiero, J. Filippi, M. Innocenti, A. Marchionni, H.A. Miller, F. Vizza, Chemcatchem 7 (2015) 2214 2221.

[18] M. Shao, J. Power Sources 196 (2011) 2433-2444.

[19] L. Zhang, Q. Chang, H. Chen, M. Shao, Nano Energy 29 (2016) 198-219.

[20] M.A.F. Akhairi, S.K. Kamarudin, Int. J. Hydrogen Energy 41 (2016) 4214-4228.

[21] W. Xu, Y. Gao, T. Lu, Y. Tang, B. Wu, Catal. Lett. 130 (2009) 312-317.

[22] L.A. Estudillo-Wong, A.M. Vargas-Gomez, E.M. Arce-Estrada, A. ManzoRobledo, Electrochim. Acta 112 (2013) 164-170.

[23] Y.-H. Qin, Y. Zhuang, R.-L. Lv, T.-L. Wang, W.-G. Wang, C.-W. Wang, Electrochim. Acta 154 (2015) 77-82.

[24] X. Cao, L. Wang, Y. Wang, Q. Xu, Q. Li, Chem. J. Chinese Universities-Chinese 36 (2015) 1187-1193.

[25] E.A. Monyoncho, S. Ntais, N. Brazeau, J.J. Wu, C.L. Sun, E.A. Baranova, Chemelectrochem 3 (2016) 218-227.

[26] F. Hu, F. Ding, S. Song, P.K. Shen, J. Power Sources 163 (2006) 415-419.

[27] C. Xu, P.K. Shen, Y. Liu, J. Power Sources 164 (2007) 527-531.

[28] S. Uhm, Y. Yi, J. Lee, Catal. Lett. 138 (2010) 46-49.

[29] Y. Wang, S.Y. Wang, X. Wang, Electrochem. Solid State Lett. 12 (2009) B73B76.

[30] J. Zhang, X. Ma, Z. Li, C. Dong, J. Nanosci. Nanotechnol. 14 (2014) 7242-7249.

[31] S.H. Lee, W. Park, B.H. Lee, W.B. Kim, J. Mater. Chem. A 3 (2015) 13492-13499.

[32] W. Wang, Y. Yang, Y. Liu, Z. Zhang, W. Dong, Z. Lei, J. Power Sources 273 (2015) 631-637.

[33] D. Chu, J. Wang, S. Wang, L. Zha, J. He, Y. Hou, Y. Yan, H. Lin, Z. Tian, Catal. Commun. 10 (2009) 955-958.

[34] U. Martinez, A. Serov, M. Padilla, P. Atanassov, Chemsuschem 7 (2014) 23512357.

[35] I.A. Rutkowska, D. Marks, C. Perruchot, M. Jouini, P.J. Kulesza, Colloids Surf. APhysicochem. Eng. Aspects 439 (2013) 200-206.

[36] K.S. Lee, I.S. Park, Y.H. Cho, D.S. Jung, N. Jung, H.Y. Park, Y.E. Sung, J. Catal. 258 (2008) 143-152.

[37] D.J. Guo, J. Power Sources 196 (2011) 679-682.

[38] C.Q. Pan, Y.Z. Li, Y.H. Ma, X. Zhao, Q.H. Zhang, J. Power Sources 196 (2011) 6228-6231.

[39] L. Fang, X.M. Luo, S. Saipanya, X.P. Huang, F.F. Li, Chiang Mai J. Sci. 43 (2016) 1223-1229.

[40] M.L. Dou, M. Hou, F. Wang, D. Liang, Q. Zhao, Z.G. Shao, B.L. Yi, J. Electrochem. Soc. 161 (2014) F1231-F1236.

[41] V. Avila-Vazquez, M. Galvan-Valencia, J. Ledesma-Garcia, L.G. Arriaga, V.H Collins-Martinez, C. Guzman-Martinez, I.L. Escalante-Garcia, S.M. DuronTorres, J. Appl. Electrochem. 45 (2015) 1175-1185.

[42] S. Cavaliere, I. Jimenez-Morales, G. Ercolano, I. Savych, D. Jones, J. Roziere Chemelectrochem 2 (2015) 1966-1973.

[43] L.M. Sun, Z.R. Liu, Y.R. Bao, H.X. Li, W.Y.G. Bao, Int. J. Mater. Res. 105 (2014) 584-587.

[44] W. Qu, Z. Wang, X. Sui, D. Gu, Int. J. Hydrogen Energy 39 (2014) 5678-5688.

[45] D.V. Leff, L. Brandt, J.R. Heath, Langmuir 12 (1996) 4723-4730.

[46] A.S. Bandarenka, M.T.M. Koper, J. Catal. 308 (2013) 11-24.

[47] C.W. Hoerr, H.J. Harwood, J. Phys. Chem.-Us 56 (1952) 1068-1073.

[48] D.A.J. Rand, R. Woods, J. Electroanal. Chem. 31 (1971), 29-\&.

[49] A. Czerwinski, J. Electroanal. Chem. 379 (1994) 487-493.

[50] W.F. Lin, S.G. Sun, Electrochim. Acta 41 (1996) 803-809.

[51] B.C. Cullity, Elements of X-ray Diffraction, second ed., Addison-Wesley Publishing Company, Inc., London, 1978.

[52] R. Kurchania, D. Rathore, R.K. Pandey, J. Mater. Sci.-Mater. Electron. 26 (2015) 9355-9365.

[53] H.J. Wasserman, J.S. Vermaak, Surf. Sci. 22 (1970) 164-172.

[54] C. Solliard, M. Flueli, Surf. Sci. 156 (Part 1) (1985) 487-494.

[55] X. Li, Q. Huang, Z. Zou, B. Xia, H. Yang, Electrochim. Acta 53 (2008) 6662-6667.

[56] F.I. Pires, H.M. Villullas, Int. J. Hydrogen Energy 37 (2012) 17052-17059.

[57] T. Ohba, H. Kubo, Y. Ohshima, Y. Makita, N. Nakamura, H. Uehara, S. Takakusagi, K. Asakura, Chem. Lett. 44 (2015) 803-805.

[58] B. Ravel, M. Newville, J. Synchrotron Radiat. 12 (2005) 537-541.

[59] A.K. Shukla, R.K. Raman, N.A. Choudhury, K.R. Priolkar, P.R. Sarode, S. Emura, R. Kumashiro, J. Electroanal. Chem. 563 (2004) 181-190.

[60] S. Mukerjee, J. McBreen, J. Electrochem. Soc. 146 (1999) 600-606.

[61] T.T.H. Van, C.J. Pan, J. Rick, W.N. Su, B.J. Hwang, J. Am. Chem. Soc. 133 (2011) $11716-11724$

[62] T. Iwasita, E. Pastor, Electrochim. Acta 39 (1994) 531-537.

[63] P.A. Christensen, S.W.M. Jones, A. Hamnett, J. Phys. Chem. C 116 (2012) 24681 24689.

[64] Z.-Y. Zhou, Q. Wang, J.-L. Lin, N. Tian, S.-G. Sun, Electrochim. Acta 55 (2010) 7995-7999.

[65] G. Tremiliosi-Filho, E.R. Gonzalez, A.J. Motheo, E.M. Belgsir, J.M. Leger, C. Lamy, J. Electroanal. Chem. 444 (1998) 31-39.

[66] S. Mukerjee, J. McBreen, J. Electroanal. Chem. 448 (1998) 163-171. 